Association for Information Systems AIS Electronic Library (AISeL)

AMCIS 1998 Proceedings

Americas Conference on Information Systems

(AMCIS)

December 1998

\title{
Reengineering the Human Resource Information System at Gamma
}

James Rodger

University of Pittsburgh at Johnstown

Parag Pendharkar

Pennsylvania State Capital College

Follow this and additional works at: http://aisel.aisnet.org/amcis 1998

\section{Recommended Citation}

Rodger, James and Pendharkar, Parag, "Reengineering the Human Resource Information System at Gamma" (1998). AMCIS 1998 Proceedings. 45.

http://aisel.aisnet.org/amcis1998/45

This material is brought to you by the Americas Conference on Information Systems (AMCIS) at AIS Electronic Library (AISeL). It has been accepted for inclusion in AMCIS 1998 Proceedings by an authorized administrator of AIS Electronic Library (AISeL). For more information, please contact elibrary@aisnet.org. 


\title{
Reengineering the Human Resource Information System at Gamma
}

\author{
James A. Rodger \\ University of Pittsburgh at Johnstown \\ Parag C. Pendharkar \\ Pennsylvania State Capital College
}

\begin{abstract}
In 1997, Gamma Health Care Systems embarked on a redesign project for their Human Resource Information System (HRIS). Redesign involved major changes to the existing system to guarantee a very high level of service. This case describes the efforts of the Human Resource Department (HRD) to redesign its HRIS to better meet enterprise-wide goals of cost effectiveness and efficiency. The reengineering project transformed the HRD from a historic role of transaction processing to one of a strategic partner.
\end{abstract}

\section{Description of Gamma}

Gamma is a growing health care conglomerate that is aggressively pursuing market share in the managed health care market. Gamma is located in Johnstown which is in the western region of Pennsylvania. It's tertiary area covers approximately a 250 mile radius, and includes six health care centers. Gamma employs over 3,000 health care professionals. Its HRD realized that it would have to make major changes in the HRIS to provide the level of service and support required by senior management. Senior management's goal was to strategically partner with the HRD to reduce costs and effectively meet and/or exceed the quality expectations of Gamma.

\section{Gamma's Strategy — Development of HRD as a Strategic Partner}

HRD helps to define solutions to problems of workforce utilization, organizational development, performance measurement, and adaptation to evolving business demands. In addition, HRD delivers a wide range of information services that enable the other business units to acquire, develop, deploy and reward the skill sets and competencies necessary for achieving business goals (Minneman, 1996). HRD executives recognize that the CEO expects them to be true partners in the business (Ulrich and Eichinger, 1995).

The challenge in becoming a true strategic partner is the degree to which HRD can assess current operations and come up with better ways of doing work. HRD concluded that redesign of the HRIS could significantly help them deal with this challenge. An effective HRIS can provide a set of tools for achieving support of the business of human resources (Groe, et al., 1996).

The focus on HRIS redesign is a paradigm shift for the organization. Previously, Gamma operated with a patchwork of stand-alone human resource applications. Databases that kept track of personnel transactions were not integrated. Redesign enabled the HRD to transform its administrative legacy of red tape into a more strategic orientation. HRIS redesign is nothing new to the health care industry. In many organizations, HRDs and information systems departments are collaborating on enterprise-wide systems designed to provide management with critical information about workforce issues (Santosus, 1995). The comprehensive base of accurate, up-to-date, and readily accessible human resource information that these systems can provide is absolutely essential to the HRD's ability to perform its key roles (Minneman, 1996).

\section{Reengineering the "Early Win" at Gamma}

Gamma's reengineering effort was initiated in the Summer of 1996, and implemented in the Fall of 1997. HRIS redesign is expected to reduce costs by $\$ 23$ million over the next three years. Several "early wins" have already been identified:

- Gamma has achieved a complete upgrade to the newest version of the HRIS

- Gamma has consolidated affiliate HRISs into an integrated human resource and payroll system

\section{Objectives}

The primary objective of the research was to provide Gamma management an assessment of the progress of the reengineering project. The researchers made use of a questionnaire and interviews to assess the situation. Several items were measured concerning the HRIS:

- Level of satisfaction with the personal transaction process

- Desirability of additional information from reports

- Confidentiality regarding access and distribution of information 
- Level of training provided for employees in the use of the system

- Capability awareness of employees for the system

- Desirability for more hands-on use of the system

\section{Data Collection and Methodology}

The case study analysis of Gamma began with a site visit in early July, 1997. Data were gathered from interviews, annual reports, and a questionnaire. One hundred and fifteen (115) surveys were sent to HRIS users at Gamma. Sixty-nine (69\%) of the surveys were returned. Ten interviews were conducted with Gamma executives, including the Director of HR, the Director of IS, the Director of Microbiology, the Chairman of the Board of Directors, the Director of Anesthesiology, the Director of Radiology, the Director of Laboratory Services, the Director of Infection Control, the Director of Pharmacy, and the Director of Pathology. Contact has been maintained via fax and telephone. Several other visits have been made during 1998.

\section{Results}

Results of the questionnaire provided several insights into the progress of the reengineering project. The findings suggest that more improvements in the reengineering process are necessary. For example, a majority of customers reported that the personal transaction process (PER-1) procedures and forms for the HRIS were not user friendly. Frequency analysis indicated that $7.2 \%$ of users reported the PER-1 as definitely not user friendly, $76.8 \%$ reported them as not user friendly, $4.3 \%$ reported that the PER-1 was neither user friendly nor not user friendly, 11.6\% said the PER-1 was user friendly and no users said the PER-1 was definitely user friendly. A significant majority of respondents would prefer a simplified PER-1 procedure and form for personnel transactions. Twenty five percent (25\%) of users would prefer to communicate via electronic mail, and five percent $(5 \%)$ would prefer HRIS transactions to be conducted using voice mail. Only ten percent (10\%) of users indicated that they would desire additional reports to be generated from the HRIS. One hundred percent (100\%) of users of the HRIS consider the distribution and collection of reports to be handled in a confidential manner. Users unanimously agreed that they were satisfied with the content and frequency of the HRIS reports.

The directors of the various departments who were interviewed expressed their concern about the need for more user training on the HRIS in order to help managers utilize this tool for decision making. In addition, the directors felt that there was a very real need for managers and employees to become more aware of the potential uses of the HRIS.

\section{Conclusions and Recommendations}

The research suggests that Gamma has made great strides toward an integrated its HRIS. However, several problems remain. While the information technology infrastructure - databases, software, hardware, and networks - is in place, there are no guarantees that the system is being used for better management of human resource information. In fact, the study revealed that users, managers, and employees are unaware of the value-added potential of the system.

The study helped the researchers identify several recommendations. First, there is a high level of dissatisfaction with the present PER-1 forms and procedures. Personnel transaction forms should be redesigned to provide a more user-friendly process. Second, additional training is necessary to provide managers and employees hands-on experience and exposure to the new features of the HRIS. Third, the HRD must concentrate on communicating and educating users to help them become aware of the value-added potential of the HRIS. Fourth, the HRD should strive to maintain user satisfaction with the content, frequency, and confidentiality of HRIS reports. Finally, the HRD should propose follow-up interviews and a second survey to access any changes in user perceptions of the redesigned personnel transaction process, training programs, and communication and education improvements.

References available upon request.

References 